\title{
Cellular and Humoral Immunity in Recurrent Respiratory Syncytial Virus Infections
}

\author{
G. W. FERNALD, ${ }^{(26)}$ J. R. ALMOND, AND F. W. HENDERSON \\ Department of Pediatrics, University of North Carolina School of Medicine, Chapel Hill, North Carolina USA
}

\begin{abstract}
Summary
A study of humoral and cellular immune responses to respiratory syncytial virus (RSV) was carried out in a research day care center over a period of $\mathbf{1 0}$ years. To analyze the cumulative effect of recurrent RSV infections, children were grouped by years of potential RSV exposure. RSV epidemics were documented each year from 1967 through 1979. Most epidemics occurred in January and February, but occasional RSV isolations were made in December or as late as May. Neutralizing antibodies to RSV were assayed in serum obtained in the fall and spring of each year. These data indicate that the majority of children became infected in each of the first 3 years of life. Cellular immunity, expressed as RSV-stimulated lymphocyte blastogenesis, was assayed in fall and spring blood samples during the latter 4 years of the study. The mean lymphocyte stimulation index (SI) was near unity before the first infection and rose gradually during year 1, 2, and 3 to a level of approximately 4.0 thereafter. To determine whether in vitro measures of immunity to RSV correlated with resistance to subsequent infection, the effect of antibody level on infection rates was examined. The infection rate for children with pre-existing titers of <16 was significantly higher than those with titers of 16 or greater, but infections also occurred in children with high titers. The effect of pre-existing cell-mediated immunity, as expressed by antigen-stimulated lymphocyte blastogenesis, also was analyzed. More children with low stimulation indices $(<3.0)$ were infected but the difference between low and high reactors was not significant. When the combined effect of antibody titer and SI on infection rates was examined, protection correlated with serum antibody but no added effect could be related to CMI. The relationship of lymphocyte SI and clinical illness was examined by grouping subjects according to clinical illness syndromes associated with proven RSV infection. SI were statisticaly similar regardless of age or illness syndrome. Similar comparisons with preillness antibody titers revealed an inverse relation between height of titer and severity of clinical illness. Data derived from this prospective study of RSV infection do not support the hypothesis that cell-mediated immunity contributes significantly to resistance to infection or to disease pathogenesis. Because neither systemic humoral nor cell-mediated immunity appear to act directly in modifying RSV infection and disease expression, it is speculated that local immune mechanisms within the respiratory tract may be involved.
\end{abstract}

\section{Abbreviations}

CMI, cell-mediated immunity

LRI, lower respiratory illness

RSV, respiratory syncytial virus

SI, stimulation index

URI, upper respiratory illness

RSV is the most frequent cause of lower respiratory tract infections in infancy and early childhood $(2,6,8)$. In addition to causing severe bronchiolitis and pneumonia in the first year of life, RSV reinfects children annually, producing winter epidemics of both lower and upper respiratory disease $(9,20)$. Studies on the pathogenesis of RSV disease have suggested a role for both humoral and cell-mediated immunity $(2,4,25)$. These investigations were based on patients seen during and after acute RSV infections, most of whom were ill enough to be admitted to a hospital. Longitudinal studies of acute respiratory infections in non-hospitalized children have provided a broader view of the spectrum of disease caused by RSV and suggest that although nearly all children become infected, very few require hospitalization (3).

This study of humoral and cellular immune responses to RSV infections was carried out in a research day care center population over a period of 10 years. The accumulated data on clinical disease expression, virus isolations, serologic and in vitro lymphocyte responses provide a basis from which the effects of immunity on resistance to $\mathrm{RSV}$ infection and on disease pathogenesis can be studied.

\section{MATERIALS AND METHODS}

Children attending the Frank Porter Graham Child Development Center comprised the study population. As part of a multidisciplinary research program, investigations on the etiology and epidemiology of acute respiratory disease in this group have been carried out since 1966. Subjects are entered at 6-12 wk of age after the nature of the research projects has been explained and informed consent has been obtained from the parents. Daily medical surveillance is provided and all illnesses are documented and treated by the staff. Routine viral cultures are obtained from the upper respiratory tract every 2 wk and at the first sign of acute respiratory disease. Venous blood samples are obtained each fall and spring for serologic and immunologic studies. Details of the study population and its management are published elsewhere $(9$, 16). Consent for participation, including collection of cultures and semiannual venous blood samples, was obtained each year from parents of the subjects. Consent forms and study design were reviewed and approved annually by the UNC School of Medicine Committee for the Protection of the Rights of Human Subjects.

Serum neutralizing antibodies to RSV were assayed in a microtitration system by standard techniques (9). The starting dilution was 1:8 and a 4-fold rise in titer between consecutive samples was considered the minimum criterion for evidence of infection.

Lymphocyte cultures were prepared from heparinized whole blood specimens stored at room temperature up to $18 \mathrm{~h}$ from the time of venipuncture. Repeated comparison of samples tested immediately and held overnight showed no loss of lymphocyte responsiveness to phytohemagglutinin or several test antigens. Blood samples were diluted 1:10 with RPMI 1640 culture medium (Gibco) and 1-ml aliquots were dispensed in $12 \times 75 \mathrm{~mm}$ polypropylene tubes with snap caps (Falcon \#2063). A $0.025 \mathrm{ml}$ portion of antigen, $10 \mu \mathrm{g}$ Phytohemagglutinin (Famitogen, Burroughs Wellcome), or diluent control was added to quadruplicate 
sets of culture tubes. RSV antigen was prepared from the Long strain grown in Hep-2 cells to a titer of $10^{6}$ TCID $_{50}$, concentrated in polyethylene glycol (18), and stored at $-70^{\circ} \mathrm{C}$ until used. Uninfected Hep-2 cell cultures, processed similarly, served as the antigen control. Dilutions of the RSV antigen ranging from 1:5 to 1:25 stimulated approximately the same level of lymphocyte reactivity in $80 \%$ of adult volunteers tested. A single 1:10 antigen dilution was utilized because of the limited amount of blood available from the children and because it provided the maximum reactivity with the least background stimulation. Cultures were incubated at $37^{\circ} \mathrm{C}$ in a humidified atmosphere of constantly monitored $5 \% \mathrm{CO}_{2}$ and air (Forma Scientific). After 5 days, cultures were pulsed with $1 \mu \mathrm{Ci}$ methyl- $\left[{ }^{3} \mathrm{H}\right]$ thymidine (Schwarz/ Mann $1.9 \mathrm{Ci} / \mathrm{mmole}$ specific activity) for $4-6 \mathrm{~h}$. Cells were washed twice with $2 \mathrm{ml} \mathrm{3 \%}$ acetic acid, once with cold 5\% trichloracetic acid and once with $100 \%$ methanol. Cell buttons were then bleached with $0.05 \mathrm{ml} \mathrm{H} \mathrm{O}_{2}$, dissolved in $0.5 \mathrm{ml}$ Soluene-350 (Packard Instrument Company, Inc.), mixed with $4 \mathrm{ml}$ scintillation fluid and counted in a Packard Model 3385 Tri-Carb Scintillation Counter. Mean counts per minute were calculated after exclusion of outlyers and the ratio of antigen stimulated cpm to control cpm was taken as the SI.

\section{RESULTS}

Documentation of recurrent RSV infections. To study the cumulative effect of recurrent RSV infections on humoral and cellmediated immunity, children were grouped by years of potential RSV exposure (Fig. 1). Cultures of upper respiratory secretions, obtained biweekly throughout the year and at the onset of any respiratory illness, yielded RSV in $\mathbf{4 0 \%}$ of 77 children at risk in the first year of life and $41 \%$ of 76 in the second. During the third year, $21 \%$ of 75 children and in the fourth season $20 \%$ of 71 children had positive cultures. Subsequently, less than $10 \%$ were reinfected annually as demonstrated by viral isolation. RSV epidemics were documented at the Center each year from 1967 through 1979, except for 1977 when neither RSV infection nor typical clinical illness was observed. Most epidemics occurred in January and February, but occasional RSV isolations were made in December or as late as May.

Neutralizing antibodies to RSV were assayed in serum obtained in the fall and spring of each year over the 10-year period of observation. These bleedings were carefully timed to circumvent anticipated or recent RSV epidemics or other respiratory virus infections which might alter the donor's immune status. Although acute and convalescent patient sera relative to illnesses were not obtained, these bleedings did indicate the antibody status of

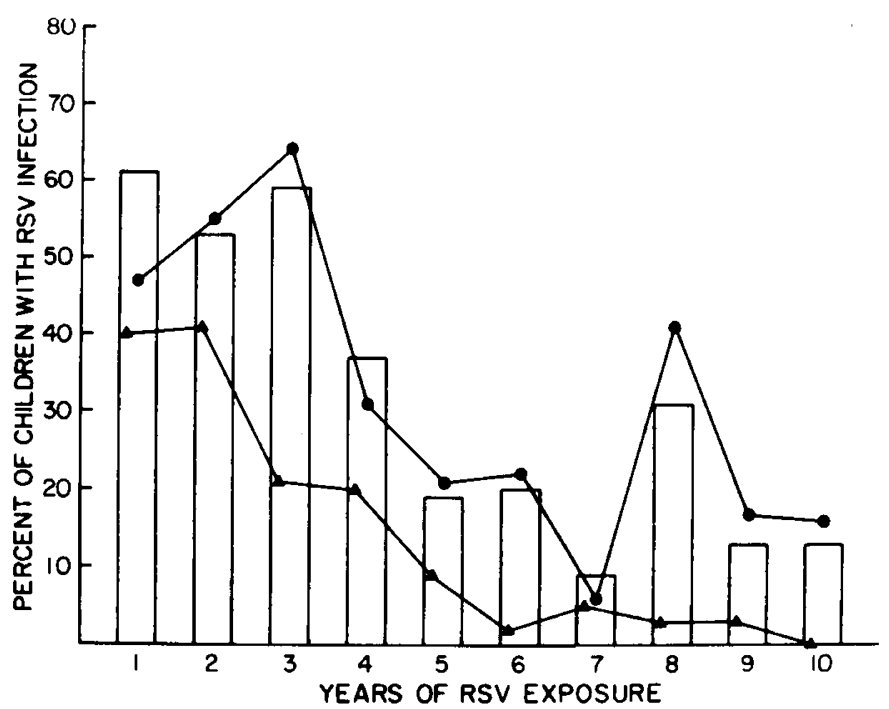

Fig. 1. Rate of respiratory syncytial virus (RSV) infection by year of exposure. $\triangle$, RSV isolates; $O$, 4-fold neutralizing antibody titer rises; and vertical bars show total RSV infections. subjects within 30-90 days of each RSV season. As shown in Figure 1, the rate of sero-conversion increased from $47 \%$ in the first year of exposure to $64 \%$ in the third year and then declined to a mean of 22\% per year for ages 4-10. Although more timely serologic studies might have increased the number of titer rises, $83 \%$ of children with culture proven infections maintained a 4 fold or higher titer rise in the spring bleeding, indicating that the serologic response in these subjects endured for several months. In fact, mean titer levels remained significantly higher than preinfection titers in the next fall bleeding, 1 year later.

These data indicate that the majority of children become infected in each of the first 3 years of life. Eighty-six percent of the children had serologic evidence of RSV infection by the end of the second year and $99 \%$ had been infected at least once by the third year. Infection rates, based upon the combination of positive viral cultures and serologic rises, are depicted by vertical bars in Figure 1. This profile of RSV infection rates by year of exposure serves as a background to subsequent sections dealing with host immune responses to RSV.

In vitro lymphocyte response to recurrent $R S V$ infections. Cellular immunity, expressed as RSV-stimulated lymphocyte blastogenesis, was assayed in fall and spring blood samples obtained during the last $\mathbf{4}$ years of the study. The mean lymphocyte SI was near unity before the first infection, rose gradualy during years 1,2 , and 3 , and then leveled off at approximately 4.0 before and after documented infections. Table 1 provides an analysis of lymphocyte reactivity to RSV in subjects with multiple documented infections. Pre-infection SI were significantly lower than postinfection levels related to the first and second RSV infections. Lymphocyte reactivity remained elevated through the next fall bleeding. The lack of significant response to the third infection resulted from the sustained level of fall reactivity as well as a somewhat lower level of rise following subsequent reinfection.

Effect of humoral and cell-mediated immunity on recurrent $R S V$ infection. To determine whether in vitro measures of immunity to RSV correlated with resistance to subsequent infection, the effect of antibody level on infection rates was examined (Table 2).

Table 1. Development of cell-mediated immunity after recurrent respiratory syncytial virus infection

Lymphocyte stimulation index \pm S.D. ${ }^{1}$

\begin{tabular}{|c|c|c|c|c|}
\hline $\begin{array}{l}\text { Infection } \\
\text { no. }\end{array}$ & $\begin{array}{c}\text { No. } \\
\text { subjects }\end{array}$ & $\begin{array}{l}\text { Pre-infection } \\
\text { (FALL) }\end{array}$ & $\begin{array}{l}\text { Post-infection } \\
\text { (SPRING) }\end{array}$ & $\begin{array}{l}\text { Late convalescent } \\
\text { (FALL) }\end{array}$ \\
\hline 1 & 10 & $0.98 \pm 1.35-$ & $23.66 \pm 1.73$ & $-1.86 \pm 1.75$ \\
\hline 2 & 17 & $1.63 \pm 1.60-$ & $-3.96 \pm 2.55$ & $3.26 \pm 2.32$ \\
\hline 3 & 10 & $1.92 \pm 1.64$ & $2.99 \pm 2.23$ & $2.77 \pm 2.04$ \\
\hline
\end{tabular}

Table 2. Effect of pre-existing neutralizing antibody on respiratory syncytial virus (RSV) infection rates

\begin{tabular}{|c|c|c|c|c|c|c|}
\hline \multirow[b]{3}{*}{$\begin{array}{c}\text { Prior RSV } \\
\text { exposure }\end{array}$} & \multicolumn{6}{|c|}{ Antibody titer before RSV season } \\
\hline & \multicolumn{3}{|c|}{$<16$} & \multicolumn{3}{|c|}{$\geq 16$} \\
\hline & $\begin{array}{c}\text { Observed } \\
\text { no. }\end{array}$ & $\begin{array}{c}\text { Infected } \\
\text { no. }\end{array}$ & $\begin{array}{c}\text { Rate } \\
(\%)\end{array}$ & $\begin{array}{c}\text { Ob- } \\
\text { served } \\
\text { no. }\end{array}$ & $\begin{array}{c}\text { Infected } \\
\text { no. }\end{array}$ & $\begin{array}{l}\text { Rate } \\
\text { (\%) }\end{array}$ \\
\hline 0 & 36 & 30 & (83) & 19 & 10 & (53) \\
\hline 1 & 42 & 30 & (71) & 19 & 7 & (37) \\
\hline 2 & 27 & 23 & (85) & 32 & 16 & (50) \\
\hline 3 & 13 & 9 & (69) & 38 & 12 & (32) \\
\hline$\geq 4$ & 21 & 9 & (43) & 129 & 28 & (22) \\
\hline Total & 139 & 101 & (73) & 237 & 73 & (31) \\
\hline
\end{tabular}


Children with pre-infection RSV neutralization titers of $<16$ were compared with those having titers $\geq 16$. The infection rate for children with pre-existing titers $<16$ was significantly higher than those with titers above this level $\left(\chi^{2}=62 ; P<0.001\right)$. Infants in the first year, who had no prior exposure to RSV and antibody titers $<16$, were predictably susceptible to infection, although children with similarly low fall titers were equally susceptible in the second and third year of exposure. The antibody titers of $\geq 16$ in the 19 previously uninfected infants were most likely of maternal origin because most were less than 6 months of age at the time of the first fall bleeding. Cord serum titers, when available, were sufficiently elevated to account for such persisting titers (data not shown); thus, there was evidence of a relationship between serum neutralizing antibody and resistance to RSV infection.

The effect of pre-existing cell-mediated immunity, as expressed by antigen-stimulated lymphocyte blastogenesis, was analyzed in those children assessed for this parameter of CMI during the last 4 years of the study (Table 3). Based on prior experiments, a stimulation index of $\geq 3.0$ was taken as a significant expression of CMI. The high infection rate in the first year of exposure was expected in these previously uninfected infants. All infants in this first year group had an SI of $<3.0$, which was expected because CMI is not thought to be maternally derived. Resistance to infection should have become apparent as the children experienced recurrent RSV infections. Although there appears to be a higher rate of infection in subjects with SI levels below 3.0 in the second, third, and fourth year of exposure, the difference between those with low and high CMI is not significant $\left(\chi^{2}=3.61 ; P<\right.$ $0.10)$. Furthermore, if infants with 1 prior year of exposure, many of whom were not previously infected, are eliminated and only those with $\mathbf{2}$ or more years of exposure are compared, there is no difference between high and low responders $\left(x^{2}=0.29\right)$.

Although there appeared to be no direct relationship between the lymphocyte blastogenic response to RSV and resistance to infection, the question remained whether CMI might enhance the observed protective effect of antibody. The combined effect of serum antibody and lymphocyte reactivity on infection with RSV was examined as shown in Figure 2. Episodes of RSV infection documented in children aged 1 year or older were plotted as a

Table 3. Effect of pre-existing cell-mediated immuanity on respiratory syncytial virus ( $R S V$ ) infection rates

\begin{tabular}{|c|c|c|c|c|c|c|}
\hline \multirow[b]{3}{*}{$\begin{array}{l}\text { Prior RSV } \\
\text { exposure }\end{array}$} & \multicolumn{6}{|c|}{ Range of lymphocyte stimulation index } \\
\hline & \multicolumn{3}{|c|}{$\leq 2.9$} & \multicolumn{3}{|c|}{$\geq 3.0$} \\
\hline & $\begin{array}{c}\text { Observed } \\
\text { No. }\end{array}$ & $\begin{array}{c}\text { Infected } \\
\text { No. }\end{array}$ & $\begin{array}{c}\text { Rate } \\
(\%)\end{array}$ & $\begin{array}{c}\text { Ob- } \\
\text { served } \\
\text { No. }\end{array}$ & $\begin{array}{c}\text { Infected } \\
\text { No. }\end{array}$ & $\begin{array}{l}\text { Rate } \\
(\%)\end{array}$ \\
\hline 0 & 13 & 11 & (85) & $\mathbf{0}$ & $\mathbf{0}$ & $(-)$ \\
\hline 1 & 15 & 9 & (60) & 4 & 1 & (25) \\
\hline 2 & 15 & 4 & (27) & 6 & 1 & (17) \\
\hline 3 & 18 & 5 & (28) & 15 & 2 & (13) \\
\hline$\geq 4$ & 36 & 4 & (11) & 38 & 6 & (16) \\
\hline Total & 97 & 33 & (34) & 63 & 10 & (16) \\
\hline
\end{tabular}

function of both antibody titer and lymphocyte SI. Taking an antibody titer of 16 and a stimulation index of 3.0 as lower limits of biologic significance, the resulting scatter-gram was subdivided into four groups as indicated in the Figure. Analysis of numbers of infected versus not infected subjects in high antibody/low SI and high antibody/high SI groups revealed no effect of CMI on resistance to infection $\left(\chi^{2}=0.51\right)$.

Clinical illness and immunity. Severe LRI due to RSV occurs most frequently in early infancy. As shown in Table 4, this commonly recognized pattern of RSV disease was reiterated by the population under study. Standardized diagnostic criteria for LRI were employed throughout (3). During the first year, 21 lower respiratory infections were documented in 77 children; bronchiolitis accounted for 17, pneumonia three, and laryngotracheobronchitis one. Eight of nine in the second year were diagnosed as bronchiolitis and one as pneumonia. Subsequent LRIs from age 3 through 10 included bronchiolitis in eight, pneumonia in three and tracheobronchitis in two. The number of children infected annually decreased from $64 \%$ in the first year of exposure to a plateau of $18.6 \%$ after the fifth year.

There were more upper respiratory illnesses (URIs) in the second and third years than in the first, but this was followed by a sharp decrease in URIs after the third year. The frequency of asymptomatic infections increased as the URIs decreased.

It has been suggested that cell-mediated immunity, developed as a result of RSV infection, may be either protective or contribute to severity of the disease or both. If RSV-induced CMI is pathogenic, its effect should be apparent when clinical illness expression

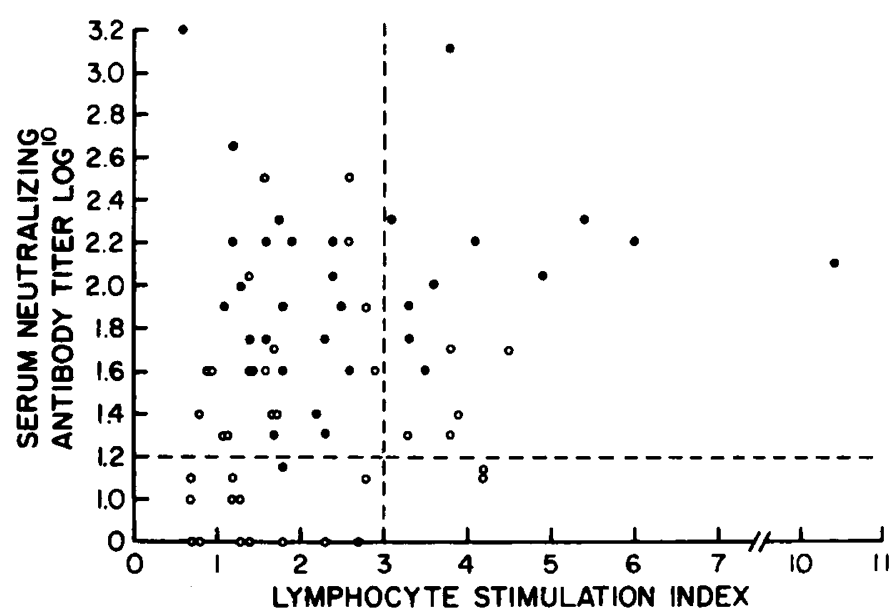

Fig. 2. The combined effects of serum antibody titer and antigenspecific lymphocyte reactivity on susceptibility to respiratory syncytial virus (RSV) infection. Coordinates represent data obtained before each RSV exposure after the first year of life. Open circles represent subjects who subsequently became infected and closed circles represent uninfected subjects. The horizontal (.-.-.-...--) line delineates serum antibody titers above and below $1: 16$ and the (vertical ............. line) indicates a lymphocyte stimulation index of 3.0 (see text for statistical analysis).

Table 4. Clinical illnesses related to recurrent respiratory syncytial virus (RSV) infection

\begin{tabular}{|c|c|c|c|c|c|}
\hline \multirow{2}{*}{$\begin{array}{l}\text { RSV-related } \\
\text { illness } \\
\text { categories }\end{array}$} & \multicolumn{5}{|c|}{ Cumulative seasons exposed to RSV } \\
\hline & \multicolumn{5}{|c|}{ Number of episodes obeerved (\%) } \\
\hline LRI & $21(27.3)$ & $9(11.8)$ & $5(6.7)$ & $5(7.0)$ & $5(2.1)$ \\
\hline URI & $23(30.0)$ & $29(38.2)$ & 31 (41.3) & $8(11.3)$ & $13(5.5)$ \\
\hline Well & $5(6.5)$ & $4(5.3)$ & $8(10.7)$ & $13(18.3)$ & $26(11.0)$ \\
\hline Total Infected & $49(64)$ & $42(55.3)$ & $44(58.7)$ & $26(36.6)$ & $44(18.6)$ \\
\hline Not Infected & $28(36)$ & $34(44.7)$ & $31(41.3)$ & $45(63.4)$ & $192(81.4)$ \\
\hline Total Observed & $77(100 \%)$ & $76(100)$ & $75(100)$ & $71(100)$ & $236(100)$ \\
\hline
\end{tabular}




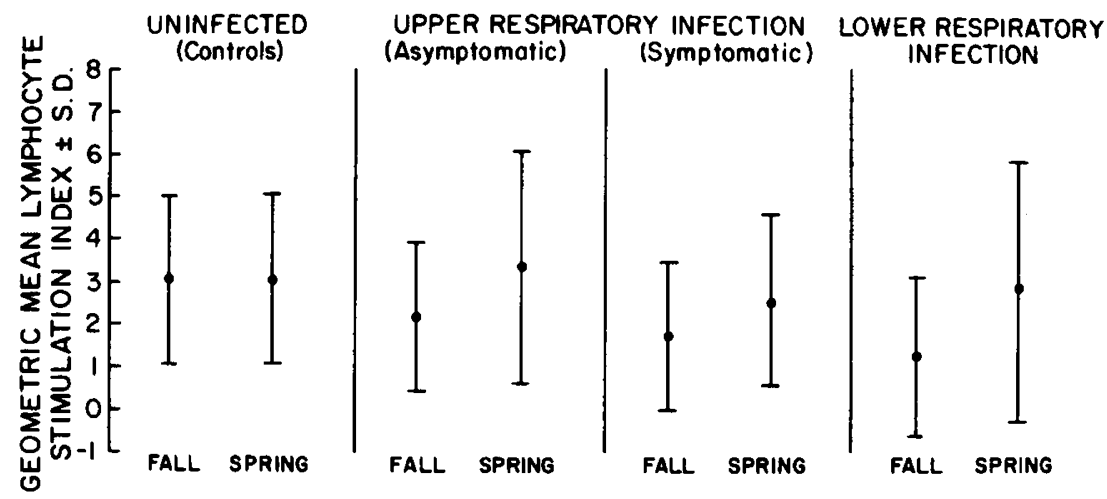

Fig. 3. Lymphocyte stimulability and clinical illness expression related to respiratory syncytial virus (RSV) infection in childhood (see text for statistical analysis).
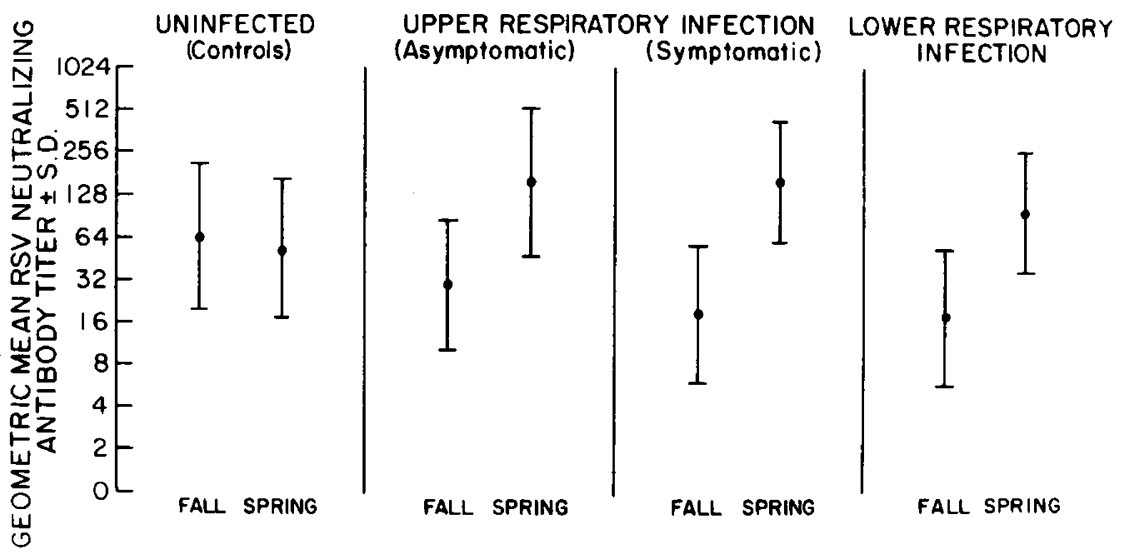

Fig. 4. Serum antibody titers and clinical illness expression related to respiratory syncytial virus (RSV) infection in childhood (see text for statistical analysis).

is compared with the subject's level of lymphocyte SI and type of clinical illness. Subjects were grouped according to clinical illnesses associated with documented RSV infections. Children who experienced neither infection nor illness during each annual RSV epidemic served as controls. Illness categories of upper respiratory and lower respiratory infection were determined clinically according to standardized criteria (3). Of the 14 children with LRI in Figure 3, $11(79 \%)$ had bronchiolitis, one had pneumonia and two had tracheobronchitis.

As illustrated in Figure 3, lymphocyte SI levels after URI or LRI were not different from those of uninfected controls. Although LRI was more common in infancy and URI more common in older children (Table 4), mean SI levels were no different from children less than 3 than over 3 years of age; therefore, all ages were combined in this Figure. Pre-infection SI levels were highest in the uninfected controls and decreased as the degree of illness increased. Only in the LRI group were pre- and postinfection SI levels significantly different $(t=2.04 ; P=0.05)$. The trend towards lower mean pre-infection SI and extent of respiratory illness, although not statistically significant, suggests a relationship between acquired immunity and severity of disease expression, perhaps due to antibody-mediated resistance to infection as suggested above.

A parallel analysis of clinical illness expression and level of RSV neutralizing antibody is shown in Figure 4. In this situation, a 4-fold or greater increase in mean titer resulted from RSV infection, regardless of clinical syndrome $(P<0.001$ for all three infected groups). Analysis of children less than 3 years of age showed no difference from the total group, suggesting that the level of response was not a function of age but rather of the level of antibody before infection or reinfection. This is also implied by the lower antibody titer levels of patients with symptomatic infec- tions compared to those with asymptomatic infections and uninfected controls.

\section{DISCUSSION •}

The role of the host immune response in respiratory syncytial virus disease remains a perplexing problem. RSV infections occur in the face of serum antibody in older patients (11) and in early infancy, despite significant levels of maternally derived antibody (21). Henderson et al. (9) studied the relationship between RSV infections and clinical disease expression in the FPG Day Care Center population and, during epidemics of RSV, found the attack rate for first infections to be $98 \%$. Second infections occurred in $75 \%$ of children at risk and third infections occurred in $65 \%$. Although there was no evidence of reduction in degree of illness with second infections, severity of clinical disease expression was less with the third infection, suggesting that protective immunity was acquired as a result of repeated infection.

In the present study, infection rates were calculated per year of exposure based on the assumption that all children in the Day Care Center were at risk every year $(12,15)$. Because viral culture techniques and antibody assays may fail to detect a portion of infected patients, these data represent the minimum number of children with proven infections. The possibility that infection with different RSV strains might be missed when serum neutralization tests are performed with a single prototype strain could also interfere with detection of all patients infected (10). Nevertheless, the infection rates we observed in this study are comparable to published data (2). Thus, the FPG Day Care Center population provides a suitable data base for a long term study of the role of CMI in RSV disease.

In early studies the observation that the most severe RSV 
infections occurred in early infancy, when maternally derived antibody titers were the highest, led to speculation that antibody was involved in the pathogenesis of the disease $(1,4,5)$. More recent studies have cast doubt upon the role of maternal antibody in RSV bronchiolitis because older infants who lack detectable levels of serum antibody suffer degrees of illness similar to infants in the early months of life (20). Glezen et al. (7) have reported that infection rates are related inversely to serum antibody titers in early infancy and suggest that maternal antibody may, in fact, be relatively protective.

In the present study, an analysis of infection rates relative to neutralizing antibody levels before exposure revealed that children with high antibody titers had significantly fewer infections; however, because infections did occur in the face of elevated titers in some patients, this may not have been due to a directly protective effect of serum antibody. Because fall bleedings in these patients preceded RSV epidemics by 2-3 months, titers could have fallen further before the time of infectious exposure. The strong tendency for antibody titers of uninfected subjects to remain constant (Fig. 4) from fall to spring makes this unlikely.

In the absence of evidence that humoral immunity contributes to the pathogenesis of RSV disease, cell-mediated immunity has recently come under scrutiny. Lymphocyte transformation, induced in vitro by RS virus, has been utilized in several studies as a measure of CMI. Kim et al. (14) reported that a significant response to RSV was found in lymphocytes of individuals who had undergone natural infection and/or had been given an inactivated RSV vaccine. They proposed that CMI might have contributed to the adverse reaction to infection observed in these vaccines. Scott et al. (24) studied in vitro lymphocyte transformation activity in hospitalized infants and children at the onset of RSV illness and up to 5 months thereafter. They noted a significant SI in 78\% of the infants younger than 6 months, but in only $46 \%$ of older patients. On the basis of these observations, they suggested that cell-mediated hypersensitivity might contribute to the pathogenesis of RSV disease in infancy. Schauf et al. (21) studied lymphocyte transformation responses to infants and children 3-14 days after onset of URI and LRI. They found significant SI in those who had evidence of infection, but none in a group of infants and children without respiratory disease and none in 12 newborn infants. Comparing the level of response before and after the age of 6 months, they found less reactivity in the younger subjects.

In the present study, multiple determinations of lymphocyte reactivity to RSV were performed over a period of 4 years, thereby providing data applicable to many of the questions raised above. We found that lymphocyte reactivity was minimal to absent before the first exposure to RSV and rose gradually after the first and second infections; thus, our data agree with Schauf et al. (21) but not with Scott et al. (24). Although the population in this study was ambulatory and none had disease severe enough to require hospitalization, $43 \%$ of those with documented first infections manifested lower respiratory symptoms. The numbers of children with significant LRI in subsequent years decreased sharply. The same pattern was seen for URI after the third year, suggesting that accumulating experience with RSV provided resistance to reinfection. Nevertheless, when the effect of pre-existing CMI on infection rates was evaluated, there was no statistically significant evidence that children with low SI were more susceptible than those with high levels.

Welliver et al. (25) further studied the possible role of CMI in pathogenesis of RSV infections. They found progressively increasing lymphocyte SIs in a limited number of infants with upper respiratory infections, pneumonia, bronchiolitis and asthma, respectively, and suggested this was evidence that CMI played a pathogenic role in RSV disease. To determine whether specific lymphocyte reactivity correlated with severity of disease expression in the present study, the fall and spring stimulation indices determined for children with URI and LRI (79\% had bronchiolitis) were compared with a group of uninfected controls. In this study the SI levels did not relate to severity of the clinical illnesses observed. Because Welliver et al. (25) based their conclusions on hospitalized children studied acutely and ours was a longitudinal study of children in a day care center, it is difficult to make comparisons. Nevertheless, in several ways we have demonstrated that levels of immunity resulting from RSV infection are related to subsequent resistance to reinfection and to diminished, rather than enhanced disease expression.

Because neither systemic humoral nor cell-mediated immunity appears to act directly in modifying RSV infection and disease expression, it is tempting to speculate that local immune mechanisms within the respiratory tract are involved. Either persistent low levels of secretory antibody or an anamnestic response to reinfection could be involved. Earlier studies of local antibodies to RSV employed measurement of neutralizing activity by the plaque reduction method $(13,22,23)$. The significance of these reports has been challenged by McIntosh et al. (17) who found that fluorescent-stainable IgA antibody to RSV correlated with disappearance of the virus from the respiratory tract whereas neutralizing antibody did not. To date, evidence for a protective effect of local anti-RSV antibody is unavailable. The studies of Mills et al. (19) suggested that neutralizing activity in nasal secretions did not prevent experimental infection of adult volunteers, although subsequent replication of virus was reduced. Further studies in children utilizing sensitive and reliable assays for RSV antibody are necessary to define the role of local immune mechanisms as related to disease expression in infancy and childhood.

Complete understanding of the pathogenesis of RSV disease should be sought before immunoprophylaxis of RSV infections is attempted. Although there is little evidence to support the idea that the disease process resulting from RSV infection is an expression of immune hypersensitivity, the previous adverse experience with inactivated RSV vaccine and the very young age of the population at risk dictate a high level of caution in future vaccine development efforts.

\section{REFERENCES AND NOTES}

1. Chanock, R. M., Kapikian, A. Z., Mills, J., Kim, H. W., and Parrott, P. H.: Influence of immunological factors in respiratory syncytial virus disease of the lower respiratory tract. Arch. Environ. Health, 21: 347 (1970).

2. Chanock, R. M., Kim, H. W., Brandt, C., and Parrott, R. H.: Respiratory syncytial virus. In: A. S. Evans: Viral Infections of Human. pp. 365-382 (Plenum Medical Book Company, New York, 1976).

3. Denny, F. W., Collier, A. M., Henderson, F. W., and Clyde, W. A., Jr.: Infectious agents of importance in airways and parenchymal diseases in infants and children with particular emphasis on bronchiolitis. The epidemiology of bronchiolitis. Pediatr. Res., 11: 234 (1977).

4. Gardner, P. S., McQuillin, J., and Court, S. D. M.: Speculation on pathogenesis in death from respiratory syncytial virus infection. Br. Med. J., I: 327 (1970).

5. Gardner, P. S., Turk, D. C., Aherne, W. A., Bird, T., Holdaway, M. D., and Court, S. D. M.: Deaths associated with respiratory tract infection in childhood. Br. Med. J., 4: 316 (1967).

6. Glezen, W. P., Loda, F. A., Clyde, W. A., Jr., Senior, R. J., Sheaffer, C. I., Conley, W. G., and Denny, F. W.: Epidemiologic patterns of acute lower respiratory disease of children in a pediatric group practice. J. Pediatr., 78: 397 (1971).

7. Glezen, W. P., Paredes, L., Allison, J. E., and Taber L. H.: Risk of respiratory syncytial virus infection in infants from low income families in relationship to age, sex, ethnic group and maternal antibody level. J. Pediatr., 98: 708 (1981).

8. Henderson, F. W., Clyde, W. A., Jr., Collier, A. M., Denny, F. W., Senior, R. J., Sheaffer, C. I., Conley, W. G., and Christian, R. M.: The etiologic and epidemiologic spectrum of bronchiolitis in pediatric practice. J. Pediatr., 95: 183 (1979).

9. Henderson, F. W., Collier, A. M., Clyde, W. A., Jr., and Denny, F. W. Respiratory syncytial virus infections, reinfections and immunity; a prospective longitudinal study in young children. N. Engl. J. Med., 300: 530 (1979).

10. Hierholzer, J. C. and Hirsch, M. S.: Croup and pneumonia in human infants associated with a new strain of respiratory syncytial virus. J. Infect. Dis., 140: 826 (1979).

11. Johnson, K. M., Blood, H. H., Mufson, M. A., and Chanock, R. M.: Natural reinfection of adults by respiratory syncytial virus. N. Engl. J. Med., 267: 68 (1962).

12. Kim, H. W., Arrobio, J. O., Brandt, C. D., Jeffries, B. C., Pyles, G., Reid, J. L., Chanock, R. M., and Parrott, R. H.: Epidemiology of respiratory syncytial virus infection in Washington, D.C. I. Importance of the virus in different respiratory tract disease syndromes and temporal distribution of infection. Am. J. Epidemiol., 98: 216 (1973).

13. Kim, H. W., Bellanti, J. A., Arrobio, J. O., Mills, J., Brandt, C. D., Chanock, R. 
M., and Parrott, R. H.: Respiratory syncytial virus neutralizing activity in nasal secretions following natural infection. Proc. Soc. Exp. Biol. Med., 131: 658 (1969).

14. Kim, H. W., Leikin, S. L., Arrobio, J., Brandt, C. D., Chanock, R. M., and Parrot, R. H.: Coll-mediated immunity to respiratory syncytial virus induced by inactivated vaccine or by infection. Pediatr., Res., 10: 75 (1976).

15. Loda, F. A., Clyde, W. A., Jr., Glezen, W. P., Senior, R. J., Sheafier, C. I., and Denny, F. W.: Studies on the role of viruses, bacteria and $M$. pneumoniae as causes of lower respiratory tract infections in children. J. Pediatr., 72: 161 (1968).

16. Loda, F. A., Glezen, W. P., and Clyde, W. A., Jr.: Respiratory disease in group day care. Pediatrics, 49: 428 (1972).

17. Melntosh, K., Masters, H. E., Orr, L., Chao, R. K., and Barkin, R. M.: The immunologic response to infection with respiratory syncytial virus in infants. J. Infect. Dis., 138: 24, (1978).

18. McSharry, J. and Benzinger, R.: Concentration and purification of vesicular stomatitis virus by polyethylene glycol "precipitation." Virology, 40: 745 (1970).

19. Mills, J., Van Kirk, J. E., Wright, P. F., and Chanock, R. M.: Experimental respiratory syncytial virus infection of adults. Possible mechanismes of resistance to infection and illness. J. Immunol., 107: 123 (1971).

20. Parrot, R. H., Kim, H. W., Arrobio, J. O., Hodes, D. S., Murphy, B. R., Brandt, C. D., Camargo, E., and Chanock, R. M.: Epidemiology of respiratory syncytial virus infection in Washington, D.C. Il. Infection and disease with respect to age, immunologic status, race and sex. Am. J. Epidemiol., 98: 289 (1973).

21. Schauf, V., Purcell, C., Mizen, M., and Mizen, S.: Lymphocyte transformation in response to antigens of respiratory syncytial virus. Proc. Soc. Exp. Biol. Med., 161: 564 (1979).

22. Scott, R. and Gardner, P. S.: The local antibody response to R. S. virus infection in the respiratory tract. J. Hyg. Camb., 72: 111 (1974)

23. Scott, R. and Gardner, P. S.: Respiratory syncytial virus neutralizing activity in nasopharyngeal secretions. J. Hyg. Camb., 68: 581 (1970).

24. Scott, R., Kaul, A., Scott, M., Chiba, Y., and Ogra, P. L.: Development of in vitro correlates of cell-mediated immunity to respiratory syncytial virus infection in humans. J. Infect. Dis., 137: 810 (1978).

25. Welliver, R. C., Kaul, A., and Ogra, P. L.: Cell-mediated immune response to respiratory syncytial virus infection: relationship to the development of reactive airway disease. J. Pediatr., 94: 370 (1979).

26. Requests for reprints should be addressed to: Dr. G. W. Fernald, Department of Pediatrics, University of North Carolina School of Medicine, 509 BumettWomack Clinical Sciences Building, 229H, Chapel Hill, North Carolina, 27514 (USA).

27. This research was supported by National Heart, Lung and Blood Institute grant HL19171, National Institute of Child Health and Human Development grant HD-09139, and grants R-802233, and R-804577 from the Environmental Protection Agency.

28. Received for publication October 30, 1980.

29. Accepted for publication March 1, 1983.

\title{
Post-Hepatic Insulin Secretion in the Fetal Lamb
}

\author{
JAMES S. CRESWELL, JOHN B. SUSA, RICHARD M. COWETT, ${ }^{(16)}$ \\ DENIS G. TENENBAUM, AND WILLIAM OH(17) \\ Department of Pediatrics, Women and Infants Hospital of Rhode Island and the Section of Pediatrics, Brown \\ University Program in Medicine, Providence, Rhode Island, USA
}

\begin{abstract}
Summary
Post-hepatic insalin secretion was measured in six chronically catheterized fetal lambs (fetal weight $2.8 \pm 0.3 \mathrm{~kg}$, mean \pm S.E.M.) and the results were compared with those obtained in mine prematurely delfivered newborn lambs (birth weight $3.1 \pm 0.3 \mathrm{~kg}$ and postnatal age $1.3 \pm 0.2$ days). The fetal and neonatal bonlis recetved either a $0.45 \%$ saline or a glacese infusion respectively, which resulted in a 2 -fold increase in the plasma glucose concentration. [ ${ }^{131}$ I] insulin was infused for $110 \mathrm{~min}$ to determine the rate of insultin secretion during a steady state of plasma decose concentration. Post-hepatic imsulin secretion and the metabolic elearance rate were calculated. With the 2-fold rise in plasman fucose concentration, the post-hepatic insulin secretion rate inereased significantly in the newborn lamb and in three out of four fetuses. The plasma insulin concentration mereased significantly is the fetus $(11 \pm 4.0$ to $35 \pm 8 \mu \mathrm{U} / \mathrm{ml}, P<0.05)$ during ghcose stimulation as a result of decreased metabolic clearance rate of insulin $\left(10.6 \pm 1.9\right.$ to $\left.6.3 \pm 1.8 \mathrm{ml} \cdot \mathrm{kg}^{-1} \cdot \mathrm{min}^{-1}\right)$ and an increase in post hepatic insulfn secretion rate. In spite of an increase in post hepatic insulin secretion rate, the increase is plasma insulin concentration in the newborn lamb was not significant because of lange variation $i n$ the vahues obtained. The data suggest that pancreatic beta-cells in the newborn and in the fetal lamb are equally responstre to a 2 -fold increase in plasma glucose concentration.
\end{abstract}

Incremental changes in glucose concentration influence the pancreatic beta cell secretory responses in the adult (7). Using a $\left[{ }^{131}\right.$ I]insulin turnover technique, we showed previously that the insulin secretion rate was similar between term and preterm lambs in the first week of life and that the response of the neonatal lamb to glucose stimulation was similar to that of adult sheep (6).

The relationship between glucose homeostasis and the rate of insulin production is also of importance in the fetus. Insulin can be demonstrated in fetal sheep pancreatic islet cells and plasma from 42 days of gestation onward. (1) Previously, inferences regarding the state of pancreatic beta-cell responsiveness to a glucose loading were based on observed changes in fetal plasma insulin levels in response to a glucose challenge. To date and to our knowledge there is no data on insulin kineties during the fetal period.

The purpose of this study was to evaluate the rate of net insulin secretion under basal- and glucose-stimulated conditions in the preterm fetus. The data were compared with those obtained in the neonatal period from lambs of similar gestational age.

\section{MATERIALS AND METHODS}

Fetuses from six mixed breed pregnant ewes were the subjects for our fetal studies. The mean fetal weight was $2.8 \pm 0.3 \mathrm{~kg}$ with an estimated gestational age of 130 days. Under general halothane anesthesia, indwelling polyvinyl catheters were placed in the fetal femoral artery and vein and tunneled subcutaneously to the ewe's flank. Fetal weight was estimated at the time of catheterization for calculating the dosage of $\left[{ }^{131} 1\right]$ insulin and glucose. The animals were allowed to recover at least $48 \mathrm{~h}$ before the turnover study, at which time their arterial blood gas values were as follows: $\mathrm{pH} \geq$ 